\title{
(6) OPEN ACCESS \\ Consecutive results of blood cell count and retrospective biodosimetry: useful tools of health protection regulation for radiation workers
}

\author{
Seongjae Jang, ${ }^{1}$ Jin Kyung Lee, ${ }^{1,2}$ Minsu Cho, ${ }^{1}$ Su San Yang, ${ }^{1}$ Seung Hyun Kim, ${ }^{1}$ \\ Wan Tae Kim ${ }^{3}$
}

- Additional material is published online only. To view please visit the journal online (http://dx.doi.org/10.1136/ oemed-2016-103775)

${ }^{1}$ Department of Dose Assessment, National Radiation Emergency Medical Center, Korea Institute of Radiological and Medical Sciences, Seoul, South Korea

${ }^{2}$ Department of Laboratory Medicine, Korea Cancer Center Hospital, Korea Institute of Radiological and Medical Sciences, Seoul, South Korea ${ }^{3}$ Division of Radiation Regulation, Korea Institute of Nuclear Safety, Daejeon, South Korea

\section{Correspondence to}

Dr Jin Kyung Lee, Department of Dose Assessment, National Radiation Emergency Medical Center, Korea Institute of Radiological and Medical Sciences, 75 Nowon-gil, Nowon-gu, Seoul 01812, South Korea;

jklee@kirams.re.kr

Received 17 April 2016 Revised 22 June 2016 Accepted 5 July 2016 Published Online First 28 July 2016

\section{ABSTRACT}

Background Industrial radiography is known to be one of the most vulnerable lines of work among the range of different radiation work. According to the relevant law in Korea, every worker registered in this work should check their blood cell counts every year in addition to their thermoluminescent dosimeter (TLD) doses. Since the law was enacted, however, few follow-up studies have been carried out based on the obtained results.

Objectives To ascertain the clinical usefulness of complete blood cell count (CBC) results and suggest a proper protocol of health protection for radiation workers.

Methods After reviewing all the consecutive results of CBC and TLD doses from radiation workers registered nationwide, we selected two groups of high-risk radiation workers, $\mathrm{CBC}$-high risk (CBC-HR) and TLD-high risk (TLD-HR) groups. A control group of unexposed healthy adults was also included. We compared the absorbed doses calculated by cytogenetic biodosimetry among those three groups, and examined possible confounding factors for each group.

Results Both groups of high-risk radiation workers, CBC-HR and TLD-HR, showed higher chromosome aberrations than the control group. In the control group, previous medical history of a CT scan increased the frequency of chromosome aberrations. In contrast, the frequency of chromosome aberrations in the high-risk radiation workers was affected not by the previous CT history but only by the duration of their work.

Conclusions We ascertain that reviewing consecutive results of blood cell counts and cytogenetic biodosimetry are useful complementary tools to TLD doses for health protection regulation. Several confounding factors including work duration and previous medical history need to be considered for the interpretation of biodosimetry results.

\section{INTRODUCTION}

Industrial radiography is one of the most commonly used tools in any investigation of the integrity of a component, material or system without damaging its function and structure, a process designated as non-destructive testing (NDT). For NDT, workers are usually required to handle strong $\gamma$ sources like cobalt or iridium under little supervision. Consequently, the main drawback of NDT work is that the risk of radiation hazard is relatively high compared to other lines of work where

\section{What this paper adds}

- Recently three cases of occupation-related haematological malignancies were reported in non-destructive testing company in South Korea, which were suspected of being consequences of protracted exposure to ionising radiation.

- Screening of high-risk radiation workers who might have been exposed to ionising radiation was very difficult unless the exposure was claimed. Although several abnormal annual healthcare reports were recorded before this study, nobody has ever reviewed or managed consecutive healthcare reports for industrial radiographers in South Korea.

- This is the largest cytogenetic biodosimetry study to date of a homogenous group of industrial radiographers. We found that several confounding factors including work duration and previous medical history need to be considered for the interpretation of retrospective biodosimetry results.

- We suggest that reviewing consecutive results of blood cell counts and cytogenetic biodosimetry are useful complementary tools to legal personal dose records for health protection regulation of industrial radiographers.

handling of radiation sources is better managed. ${ }^{1}$ Since occupational exposure during NDT has been a long-standing issue worldwide, international agencies have collaborated with each other extensively and with their member states to reduce the risk of occupational exposure.

Under Korean law concerning the health protection of radiography workers, registered workers are required to periodically check their personal thermoluminescent dosimeter (TLD) and to submit to a medical checkup, including a complete blood cell count (CBC), every year. ${ }^{2}{ }^{3}$ However, no follow-up process for the confirmation of an abnormality observed in the initial CBC results has been established. The legal personal TLD dose limits are $50 \mathrm{mSv}$ in any 1 year and a maximum of $100 \mathrm{mSv}$ in five consecutive years. There has been only 
minimal fluctuation in the mean personal TLD dose reported since the regulation was implemented. ${ }^{4}$ Thus, the mean dose per worker was $2.32 \mathrm{mSv}$ in 2009 and $3.71 \mathrm{mSv}$ in 2013. In addition, no case has exceeded the legal dose limit, although there were several reported cases of unreadable TLD badges due to a loss or damage. ${ }^{4}$

Nonetheless, in spite of these regulations, three cases of occupation-related haematological malignancies were recently diagnosed in workers from a small-sized radiography company even though there had been no previous reports regarding workers who had exceeded the legal dose limit. ${ }^{5}$ The incidence of these three cases of haematological malignancies has raised several important issues about the effectiveness of health protection regulations that are focused more on safety discipline to avoid exposure to radiation sources than on the health management of individual workers. Under those circumstances where TLD dose is the only legal tool to estimate a worker's exposure, worker compliance towards wearing a TLD badge must be scrutinised in order to manage exposure effectively. In situations where a TLD dose is unavailable or unreliable, cytogenetic biodosimetry should be considered as a complementary method for estimating the absorbed dose. However, it is important to realise that, in many cases, occupational exposure in NDT workers involves a low rate of exposure over a long period to relatively low levels of radiation (and not an acute exposure by accident).

The frequency of chromosome aberrations detected in peripheral blood lymphocytes has been used as an indicator of the dose of ionising radiation (IR) exposure. In cases of recent acute exposure, the most reliable method is to score dicentric chromosomes in solid-stained metaphase cells. However, we should consider a declining rate of the number of cells harbouring dicentric chromosome in order not to underestimate the dose if we perform biodosimetry several months after exposure. According to the previous study, in contrast, stable cells harbouring reciprocal translocations persist because they can survive cell division. ${ }^{6}$

The purpose of the present study was to review the effectiveness of the current healthcare regulation that requires all registered radiation workers to check their $\mathrm{CBC}$ every year in order to screen for exposed workers. In addition, the clinical usefulness of cytogenetic biodosimetry as a retrospective tool for dose estimation has been evaluated. From this study, we hope to make practical recommendations for improving the current health protection regulation.

\section{MATERIALS AND METHODS Study design}

Two groups of high-risk radiation workers, CBC-high risk (CBC-HR) and TLD-high risk (TLD-HR), were selected from radiation workers registered nationwide following a review of workers' consecutive CBC results and TLD doses which were reported by law. We regarded the TLD dose as personal dose equivalent for individual monitoring referring to the International Commission on Radiological Protection (ICRP) Publication. ${ }^{7}$ As a control, a group of healthy adults who had never been exposed to IR through their occupation was enrolled. For both of the high-risk workers groups and for the control group, we performed cytogenetic biodosimetry, a dicentric chromosome assay (DCA) and a chromosome translocation assay. After calculating the absorbed doses using the doseresponse curve which had already been constructed, we compared the doses among the three groups and examined possible confounding factors of chromosome aberrations (CAs) for each group.

\section{Selection of study population}

The protocol for recruitment followed the KIRAMS guidelines for clinical studies and was approved by the Institutional Review Board. Written informed consent for participating in the study and a detailed questionnaire on personal lifestyle (health status, occupational and medical history, involvement in radiodiagnostic procedures, smoking habits, etc) were obtained from all the participants.

\section{CBC-HR group}

Two medical technologists reviewed 25532 annual healthcare records of 8059 industrial radiographers from 52 NDT companies and categorised the results as normal or abnormal using as a reference normal intervals of $4.4-10.8 \times 10^{9} / \mathrm{L}$ for white blood cells, $120-180 \mathrm{~g} / \mathrm{L}$ for hemoglobin, and $130-450 \times 10^{9} / \mathrm{L}$ for platelets. A clinical pathologist reviewed the abnormal results and selected the cases where bone marrow suppression was suspected. The criteria for inclusion comprised one of the following conditions: (1) moderate to severe cytopenia; (2) more than two consecutive decreases in the same cell lineage; (3) bicytopenia or pancytopenia (cytopenia in two or more cell lineages). Of the 79 individuals categorised as CBC-based high-risk workers (CBC-HR), 56 agreed to participate in this study.

\section{TLD-HR group}

We sorted out all the TLD doses of industrial radiographers reported by law from 1998 to 2013 in descending order, and selected 260 workers whose TLD doses were relatively higher than others even which were within a legal limit. Among the 260 workers, 241 agreed to participate in this study as a TLD-HR group.

\section{Non-exposure control group}

As a control, 120 healthy people (aged over 20) who had never been exposed to IR for occupational purposes were recruited.

\section{Cytogenetic biodosimetry}

Analysis of dicentric chromosomes by solid Giemsa staining

Heparinised whole blood samples were processed to be cultured within 24 hours after collection. The process of culturing, harvesting, staining and scoring was performed according to previously published technical specifications developed in our laboratory, ${ }^{6}$ and in accordance with International Atomic Energy Agency (IAEA) recommendations. ${ }^{8}$

Analysis of translocation by fluorescence in situ hybridisation Heparinised whole blood samples were processed to be cultured and metaphase cells were prepared on a slide using the same protocol described in the DCA. The process of probe hybridisation for 1, 2 and 4 whole chromosome painting and the scoring criteria were previously described. ${ }^{6}$

\section{Calculation of absorbed dose}

The absorbed dose for each individual was calculated from the measured yield of dicentrics and translocations using dose-response calibration curves constructed previously. ${ }^{6}$ In brief, for the calibration curve, Co-60 was used as a source at a dose rate of $0.5 \mathrm{~Gy} / \mathrm{min}$. A linear quadratic curve containing 10 dose points $(0,0.1,0.25$, $0.5,0.75,1,2,3,4$ and $5 \mathrm{~Gy}$ ) was constructed with $95 \%$ CIs based on data concerning the yield and distribution of dicentrics and translocations for each radiation dose. The equation for dicentrics is $\mathrm{Y}=0.00146+(0.02688) \mathrm{D}+(0.07171) \mathrm{D}^{2}$. The equation for translocations is $\mathrm{Y}=0.00240+(0.01124) \mathrm{D}+(0.01752) \mathrm{D}^{2}$. 


\section{STATISTICAL METHODS}

All statistical analyses were performed using commercial software (SPSS V.22 for Windows; IBM, New York, USA). For continuous variables, data are presented as means \pm SEM. (SEs of the mean). The results obtained from CA analyses were analysed using non-parametric Mann Whitney U-tests, one-way analysis of variance (ANOVA), and Pearson's $\chi^{2}$ test. Multiple regression analysis was used to evaluate the influence of age, gender, smoking history and computed tomography (CT) or positron emission tomography (PET) diagnosis history on translocation and dicentric frequencies. Statistical significance was assumed at the $\mathrm{p}<0.05$ level.

\section{RESULTS}

\section{CA frequencies of HR radiation worker groups comparing the control group}

The main characteristics of the study participants are summarised in table 1 . The mean age of high-risk radiation workers (HR radiation workers) was higher than that of healthy controls (41.6 years vs 35.8 years, $\mathrm{p}<0.001$ ). Although HR radiation workers were mostly male, the proportion of male/female for the controls was 6 male: 4 female. Forty-seven per cent of all participants self-reported themselves as former or current cigarette smokers. Twenty-five per cent of all participants had received CT scans or PET examinations. Using this data, participants who had undergone at least one diagnostic CT scan or PET examination before blood was drawn for the study comprised the ever-CT group. The remaining 75\% reported never having received either a CT scan or PET examination (never-CT group).

A total of 417000 metaphases were analysed by both, the DCA and by the chromosome translocation assay. The CA frequency results are presented in table 2. CA analyses revealed higher aberration frequency in the HR radiation workers (CBC-HR and TLD-HR, N=297) when compared with the controls. Moreover, significant differences were observed in the dicentrics frequency (4.14 vs 1.33 dicentrics/1000 metaphases, $\mathrm{p}<0.001)$ and translocations frequency $(8.34$ vs 2.61 translocations $/ 1000$ stable metaphases, $\mathrm{p}<0.001)$. Although CA frequencies of the TLD-HR group were lower than those of the CBC-HR group ( 3.49 vs 6.93 dicentrics $/ 1000$ metaphases, $p=0.001 ; 7.87$ vs 10.36 translocations $/ 1000$ stable metaphases, $p=0.945)$, the working duration ( 16.0 years vs 13.6 years, $\mathrm{p}=0.048)$ and total cumulative dose $(82.8 \mathrm{mSv}$ vs $45.5 \mathrm{mSv}, \mathrm{p}<0.001)$ of the TLD-HR group were significantly higher than those of the CBC-HR group.

\section{Confounding factors for HR radiation worker groups and the control group}

In this study, we sought to determine whether age, gender, smoking history and diagnostic CT scan or PET history are associated with CA frequencies (dicentrics and chromosome 1, 2 and 4 translocations) in HR radiation workers and the controls. No significant differences in dicentric frequency were observed with age (ie, $<40$ years of age or $\geq 40$ years of age, $p=0.134$ ), smoking (ie, never-smokers or ever-smokers, $\mathrm{p}=0.199$ ), medical exposure history (ie, never-CT or ever-CT, $\mathrm{P}=0.059$ ), or working duration (ie, $0-10$ years, $11-20$ years or $\geq 20$ years, $\mathrm{p}=0.909$ ) subgroups (of all HR radiation workers). However, age and working duration were significantly associated with translocation frequencies $(\mathrm{p}<0.001)$.

In the control group, translocation frequencies were significantly higher in the ever-CT group than in the never-CT group (4.03 vs 2.11 translocations $/ 1000$ stable metaphases, $p<0.001$ ). Likewise, dicentric frequencies were significantly higher in the ever-CT group than in the never-CT group (2.13 vs 1.06 dicentrics $/ 1000$ metaphases, $\mathrm{p}<0.001)$. These results confirm that there is an association with medical exposure history (CT scan or PET examination before blood was drawn). Table 3 shows the results of multiple regression analyses relating age, gender, smoking history and diagnostic CT scan or PET history with translocation and dicentric frequency in the controls. These analyses revealed a significant association of age with translocation frequency $(\beta=0.150, p=0.001)$. Furthermore, history of diagnostic CT scan/PET examination significantly influenced dicentric frequency $(\beta=1.028, p<0.001)$ and translocation frequency $(\beta=4.128, p<0.001)$. The results of multiple regression analyses of age, gender and smoking history divided into the never-CT and ever-CT groups are presented in table 3. There was no statistical significance between age and CA

Table 1 General characteristics of the groups studied

\begin{tabular}{|c|c|c|c|c|c|}
\hline & \multirow[b]{2}{*}{ Total } & \multicolumn{3}{|c|}{ HR radiation workers } & \multirow[b]{2}{*}{ Controls } \\
\hline & & Whole-HR & CBC-HR & TLD-HR & \\
\hline Participants & 417 & 297 & 56 & 241 & 120 \\
\hline Age, years* (range) & $39.9 \pm 0.4(22-77)$ & $41.6 \pm 0.4(26-68)$ & $40.7 \pm 1.3(26-68)$ & $41.8 \pm 0.4(27-62)$ & $35.8 \pm 1.0(22-77)$ \\
\hline$<40$ years, $n$ & 219 & 115 & 29 & 86 & 104 \\
\hline$\geq 40$ years, $n$ & 198 & 182 & 27 & 155 & 16 \\
\hline \multicolumn{6}{|l|}{ Gender, $\mathrm{n}$} \\
\hline Female & 47 & 4 & 4 & 0 & 43 \\
\hline Male & 370 & 293 & 52 & 241 & 77 \\
\hline \multicolumn{6}{|l|}{ Smoking habits, $\mathrm{n}$} \\
\hline Never-smokers & 222 & 147 & 32 & 115 & 75 \\
\hline Ever-smokers & 195 & 150 & 24 & 126 & 45 \\
\hline \multicolumn{6}{|l|}{ Medical exposure, $n$} \\
\hline Never-CT & 313 & 223 & 39 & 184 & 89 \\
\hline Ever-CT & 104 & 74 & 17 & 57 & 31 \\
\hline Duration of radiation works, years* (range) & - & $15.5 \pm 0.5(1-34)$ & $13.6 \pm 1.1(1-30)$ & $16.0 \pm 0.5(1-34)$ & - \\
\hline Reported cumulative dose, $\mathrm{mSv}^{*}$ (range) & - & $75.9 \pm 3.2(0-418.3)$ & $45.5 \pm 7.8(0-418.3)$ & $82.8 \pm 3.4(1.8-299.2)$ & - \\
\hline
\end{tabular}


Table 2 Frequencies of chromosome aberrations for each groups by age, gender, smoking, medical history and work duration

\begin{tabular}{|c|c|c|c|c|c|c|c|c|c|c|c|c|}
\hline \multicolumn{13}{|c|}{ (A) Dicentric chromosomes } \\
\hline & \multicolumn{3}{|c|}{ Whole-HR } & \multicolumn{3}{|c|}{ CBC-HR } & \multicolumn{3}{|c|}{ TLD-HR } & \multicolumn{3}{|c|}{ Controls } \\
\hline & $\mathrm{n}$ & Dicentrics & p Value & $\mathbf{n}$ & Dicentrics & $\mathrm{p}$ Value & $\mathbf{n}$ & Dicentrics & p Value & $\mathrm{n}$ & Dicentrics & $p$ Value \\
\hline Totalt & 297 & $4.14 \pm 0.32^{* *}$ & & 56 & $6.93 \pm 1.35 * * \#$ & & 24 & $3.49 \pm 0.21 * *$ & & & $1.33 \pm 0.13$ & \\
\hline \multicolumn{13}{|l|}{ Age (years) $\dagger$} \\
\hline$<40$ & 115 & $3.69 \pm 0.39^{* *}$ & 0.134 & 29 & $4.55 \pm 1.03^{* *}$ & 0.013 & 8 & $3.40 \pm 0.38^{* *}$ & 0.324 & & $1.17 \pm 0.13$ & 0.044 \\
\hline$\geq 40$ & 182 & $4.43 \pm 0.45^{* *}$ & & 27 & $9.48 \pm 2.51$ **\#\# & & 15 & $3.55 \pm 0.26^{* *}$ & & & $1.72 \pm 0.27$ & \\
\hline \multicolumn{13}{|l|}{ Gendert } \\
\hline Female & 4 & $3.50 \pm 2.26$ & 0.498 & 4 & $3.50 \pm 2.26$ & 0.183 & & - & - & & $1.33 \pm 0.22$ & 0.862 \\
\hline Male & 293 & $4.17 \pm 0.32^{* *}$ & & 52 & $7.19 \pm 1.44^{* * \# \#}$ & & 24 & $3.49 \pm 0.21 * *$ & & & $1.34 \pm 0.16$ & \\
\hline \multicolumn{13}{|l|}{ Smoking habitst } \\
\hline Never-smokers & 147 & $3.97 \pm 0.38^{* *}$ & 0.199 & 32 & $6.72 \pm 1.24^{* * \# \#}$ & 0.894 & 11 & $3.21 \pm 0.32^{* *}$ & 0.101 & & $1.28 \pm 0.15$ & 0.694 \\
\hline Ever-smokers & 150 & $4.31 \pm 0.50^{* *}$ & & 24 & $7.21 \pm 2.73^{* *}$ & & 12 & $3.75 \pm 0.29 * *$ & & & $1.42 \pm 0.23$ & \\
\hline \multicolumn{13}{|l|}{ Medical exposuret } \\
\hline Never-CT & 223 & $4.02 \pm 0.39 * *$ & 0.059 & 39 & $6.69 \pm 1.83^{* * \#}$ & 0.183 & 18 & $3.46 \pm 0.26^{* *}$ & 0.226 & & $1.06 \pm 0.12$ & $<0.001$ \\
\hline Ever-CT & 74 & $4.52 \pm 0.50^{*}$ & & 17 & $7.47 \pm 1.58^{* * \#}$ & & 5 & $3.61 \pm 0.37^{*}$ & & & $2.13 \pm 0.29$ & \\
\hline \multicolumn{13}{|c|}{ Duration of works (years) $\ddagger$} \\
\hline $0-10$ & 94 & $4.09 \pm 0.39$ & 0.909 & 26 & $4.04 \pm 0.69$ & 0.063 & 6 & $4.10 \pm 0.47$ & 0.221 & & & \\
\hline $11-20$ & 124 & $4.32 \pm 0.64$ & & 15 & $11.73 \pm 4.42^{\#}$ & & 10 & $3.30 \pm 0.32$ & & & & \\
\hline$>20$ & 76 & $4.00 \pm 0.46$ & & 14 & $7.00 \pm 1.87^{\#}$ & & 6 & $3.24 \pm 0.32$ & & & & \\
\hline \multicolumn{13}{|c|}{ (B) Chromosome 1, 2 and 4 translocations } \\
\hline & \multicolumn{3}{|c|}{ Whole-HR } & \multicolumn{3}{|c|}{ CBC-HR } & \multicolumn{3}{|c|}{ TLD-HR } & \multicolumn{3}{|c|}{ Controls } \\
\hline & n & $\begin{array}{l}1,2,4- \\
\text { translocations }\end{array}$ & $\mathrm{p}$ Value & $\mathbf{n}$ & $\begin{array}{l}1,2,4- \\
\text { translocations }\end{array}$ & $\mathrm{p}$ Value & $\mathbf{n}$ & $\begin{array}{l}1,2,4- \\
\text { translocations }\end{array}$ & $\mathrm{p}$ Value & n & $\begin{array}{l}1,2,4- \\
\text { translocations }\end{array}$ & $p$ Value \\
\hline Totalt & 297 & $8.34 \pm 0.45^{* *}$ & & 56 & $10.36 \pm 1.74^{* *}$ & & 241 & $7.87 \pm 0.38^{* *}$ & & 120 & $2.61 \pm 0.19$ & \\
\hline \multicolumn{13}{|l|}{ Age (year) $\dagger$} \\
\hline$<40$ & 115 & $5.70 \pm 0.46^{* *}$ & $<0.001$ & 29 & $6.28 \pm 1.43^{* *}$ & $<0.001$ & 86 & $5.50 \pm 0.38^{* *}$ & $<0.001$ & 84 & $2.25 \pm 0.18$ & 0.016 \\
\hline$\geq 40$ & 182 & $10.01 \pm 0.65^{* *}$ & & 27 & $14.74 \pm 3.08^{* *}$ & & 155 & $9.18 \pm 0.52^{* *}$ & & 36 & $3.44 \pm 0.42$ & \\
\hline \multicolumn{13}{|l|}{ Gendert } \\
\hline Female & 4 & $5.00 \pm 2.38$ & 0.181 & 4 & $5.00 \pm 2.38$ & 0.206 & 0 & - & - & 43 & $1.91 \pm 0.27$ & 0.003 \\
\hline Male & 293 & $8.38 \pm 0.46^{* *}$ & & 52 & $10.77 \pm 1.86^{* *}$ & & 241 & $7.87 \pm 0.38^{* *}$ & & 77 & $3.00 \pm 0.24$ & \\
\hline \multicolumn{13}{|l|}{ Smoking habitst } \\
\hline Never-smokers & 147 & $8.90 \pm 0.66^{* *}$ & 0.294 & 32 & $11.72 \pm 2.06^{* *}$ & 0.120 & 115 & $8.11 \pm 0.60^{* *}$ & 0.767 & 75 & $2.27 \pm 0.22$ & 0.014 \\
\hline Ever-smokers & 150 & $7.79 \pm 0.62^{* *}$ & & 24 & $8.54 \pm 3.01^{*}$ & & 126 & $7.64 \pm 0.47^{* *}$ & & 45 & $3.18 \pm 0.33$ & \\
\hline \multicolumn{13}{|l|}{ Medical exposuret } \\
\hline Never-CT & 223 & $8.06 \pm 0.50$ ** & 0.415 & 39 & $8.97 \pm 2.11 * *$ & 0.013 & 184 & $7.83 \pm 0.42 * *$ & 0.736 & 89 & $2.11 \pm 0.16$ & $<0.001$ \\
\hline Ever-CT & 74 & $9.18 \pm 1.00^{* *}$ & & 17 & $13.53 \pm 3.04$ **\# & & 57 & $7.98 \pm 0.86^{*}$ & & 31 & $4.03 \pm 0.48$ & \\
\hline \multicolumn{13}{|c|}{ Duration of radiation works (year) $\ddagger$} \\
\hline $0-10$ & 94 & $5.80 \pm 0.45$ & $<0.001$ & 26 & $5.38 \pm 0.76$ & 0.018 & 68 & $5.96 \pm 0.54$ & $<0.001$ & & & \\
\hline $11-20$ & 124 & $8.27 \pm 0.76$ & & 15 & $14.47 \pm 5.05$ & & 109 & $7.42 \pm 0.48$ & & & & \\
\hline$>20$ & 76 & $11.78 \pm 1.01$ & & 14 & $15.86 \pm 3.48$ & & 62 & $10.87 \pm 0.94$ & & & & \\
\hline
\end{tabular}

†Mann-Whitney U-test.

$\ddagger$ ANOVA test with Tukey's multiple comparison.

${ }^{*} p<0.05,{ }^{* *} p<0.001$ when compared with the respective control group with Mann-Whitney U-test.

\#p<0.05, \#\#<0.001 when compared with the TLD-HR group with Mann-Whitney U-test.

ANOVA, analysis of variance; CBC-HR, complete blood cell count-high risk; TLD-HR, thermoluminescent dosimeter-high risk.

frequencies in the never-CT group. However, age significantly influenced translocation frequencies and slightly influenced dicentric frequencies in the ever-CT group.

\section{Comparing the $\mathrm{CA}$ frequencies among HR radiation workers groups: CBC-HR versus TLD-HR}

To evaluate the consequence of screening through the review of CBC results rather than TLD doses, we selected a total of 145 HR radiation workers who had recorded a dose over $250 \mathrm{mGy}$ according to the retrospective fluorescence in situ hybridisation (FISH) data. The FISH dose was estimated using chromosome 1,
2 and 4 translocation frequency in a stable metaphase (the lower limit of sensitivity of this assay was about $250 \mathrm{mGy}$ ). Twenty-eight CBC-HR radiation workers had total cumulative TLD doses of $1.3-418.3 \mathrm{mSv}$ (mean $58.7 \pm 14.5 \mathrm{mSv}$ ) during radiation work periods of $2-30$ years and 117 TLD-HR radiation workers had total cumulative TLD doses of $8.6-299.2 \mathrm{mSv}$ (mean $100.9 \pm 5.0 \mathrm{mSv}$ ) during radiation work periods of 2 34 years (table 4). Although the retrospective FISH doses of the TLD-HR group were lower than those of the CBC-HR group, the total cumulative TLD doses and annual TLD doses of TLD-HR group were higher than those of the CBC-HR group 
Table 3 Multiple regression analyses of confounding factors on translocation frequencies in the control group

\begin{tabular}{llrr}
\hline \multicolumn{4}{l}{ (A) Multiple regression analysis in the whole control group } \\
\hline Confounding factors & B-coefficient & p Value & \multicolumn{1}{c}{$95 \% \mathrm{Cl}$} \\
\hline Age (years) & 0.150 & 0.001 & 0.063 to 0.237 \\
Gender (female, male) & 1.872 & 0.123 & -0.517 to 4.261 \\
Smoking habits (Never, Ever) & 0.460 & 0.698 & -1.884 to 2.803 \\
CT (never, ever) & 4.128 & $<0.001$ & 1.912 to 6.345
\end{tabular}

(B) Multiple regression analyses in the control group by their history of CT scans

\begin{tabular}{lccc}
\hline Confounding factors & $\boldsymbol{\beta}$-coefficient & $\mathbf{p}$ Value & $\mathbf{9 5 \%} \mathrm{Cl}$ \\
\hline Never-CT group & & & \\
$\quad$ Age (years) & 0.038 & 0.399 & -0.051 to 0.127 \\
$\quad$ Gender (female, male) & 1.899 & 0.101 & -0.378 to 4.175 \\
$\quad$ Smoking habits (never, ever) & -0.674 & 0.582 & -3.069 to 1.748 \\
Ever-CT group & & & \\
$\quad$ Age (years) & 0.401 & $<0.001$ & 0.212 to 0.590 \\
$\quad$ Gender (female, male) & 4.601 & 0.179 & -2.240 to 11.443 \\
$\quad$ Smoking habits (never, ever) & 1.624 & 0.514 & -3.413 to 6.662 \\
\hline
\end{tabular}

$(\mathrm{p}<0.05)$. However, it is important to note that all recorded TLD doses were within the legal doses limits. To compare the discrimination power of TLD doses and FISH doses for the screening of 'high-risk' radiation workers among the 145 workers selected, Pearson's $\chi^{2}$ tests were conducted to check the differences in distribution (table 5). Differences were found in the ratio of FISH doses to TLD doses and annual FISH doses. If the FISH dose of an individual was five times higher than the TLD dose, the individual was classified as a 'High-risk' radiation worker since the data suggests that the frequency of TLD-wearing during working periods was relatively low. Pearson's $\chi^{2}$ test revealed a significant difference between the CBC-HR group and TLD-HR group $(\mathrm{p}<0.001, \mathrm{OR}=8.77$, 95\% CI 2.51 to 30.66). In addition, 'high-risk' radiation workers could be identified if their annual FISH doses were more than $50 \mathrm{mGy}$ (because they were potentially exposed to IR during working periods). Pearson's $\chi^{2}$ test revealed a significant difference between CBC-HR group and TLD-HR group $(\mathrm{p}=0.001, \mathrm{OR}=3.27,95 \%$ CI 1.29 to 8.27$)$.

\section{DISCUSSION}

Industrial radiographers take on the important responsibility for ensuring the safe conduct of their own work. ${ }^{19}$ The routine monitoring of these workers with monthly personal TLD records and through annual medical checkups is controlled by the Act on Nuclear Safety and Security in South Korea. ${ }^{2}$ However, although several abnormal $\mathrm{CBC}$ results were reported before this study, nobody has ever reviewed or managed consecutive healthcare reports for these workers. A personal TLD dose is the only dose measurement necessary (complementary checks are not legally required). As a result, in 2011 two cases of hematological malignancies were reported as a consequence of occupational exposure to Ir-192 and/or Co-60 at an industrial radiography company. ${ }^{5}$ Although the dose measured by the TLD badges had never been reported to exceed the legal limit, the absorbed doses of several workers, 5 according to dicentric analysis and 13 according to the translocation assay (out of a total 32 workers), were above $1.0 \mathrm{~Gy}{ }^{6}$

The current study has several strengths compared to previous studies. It is the largest cytogenetic study to date of a homogenous group of industrial radiographers. This is important since industrial radiographers represent a high-risk occupational group compared with other workers. An additional strength of our study is the methodology used to measure translocations for prolonged and repetitive IR exposure through retrospective biodosimetry. In retrospective biodosimetry, conventional scoring of dicentrics is less precise since these unstable chromosome aberrations are eliminated during the postexposure period. To elucidate if the radiation exposure was acute, chronic or experienced in the past, the determination of the frequency of translocations using the FISH technique of whole chromosome painting is more useful than DCA. Indeed, the frequency of chromosomal translocation in peripheral blood lymphocytes is currently the most reliable biomarker used for retrospective biodosimetry since long-term stability of translocation frequency was determined in industrial radiographers. ${ }^{6}{ }^{10-14}$ Theoretically, because translocation does not cause an increase or decrease in genetic material (and therefore does not cause cell death through division), radiation-induced translocations in stable cells should persist over time following IR exposure.

The background level for the total dicentrics determined in healthy controls $(1.33 \pm 0.13$ per 1000 metaphases $)$ in this study is in accordance with the findings of other studies that have reported the mean frequency of dicentrics to be between 0.35 and 1.5 per 1000 metaphases. ${ }^{15-17}$ The background level of chromosome 1, 2, and 4 translocations was determined to be $2.61 \pm 0.19$ per 1000 stable metaphases. Although the background frequencies of translocation increase significantly with age, they can vary greatly between individuals of similar age and dose history. ${ }^{18-21}$ Gender and cigarette smoking have also been observed to lead to a significant increase in translocation frequencies in some ${ }^{19} 2022$ but not all studies. ${ }^{18} 23$ A recent study

Table 4 Characteristics of the 145 HR radiation workers whose FISH doses were $\geq 250 \mathrm{mGy}$

\begin{tabular}{|c|c|c|c|}
\hline & \multicolumn{3}{|c|}{ HR radiation workers (FISH doses $\geq 250 \mathrm{mGy}$ ) } \\
\hline & Whole-HR & CBC-HR & TLD-HR \\
\hline Number of participants (group participants) & $145(297)$ & $28(56)$ & $117(241)$ \\
\hline Duration of works, years* (range) & $18.0 \pm 0.7(2-34)$ & $16.8 \pm 1.7(2-30)$ & $18.3 \pm 0.7(2-34)$ \\
\hline Cumulative TLD dose, mSv* (range) & $92.8 \pm 5.1(1.3-418.3)$ & $58.7 \pm 14.5(1.3-418.3) \dagger$ & $100.9 \pm 5.0(8.6-299.2)$ \\
\hline Mean of annual TLD doses, mSv* (range) & $6.0 \pm 0.4(0.3-37.4)$ & $3.8 \pm 0.7(0.3-19.0) \dagger$ & $6.6 \pm 0.5(1.1-37.4)$ \\
\hline Retrospective FISH dose, mGy* (range) & $491.3 \pm 18.9(284.0-1754.0)$ & $593.7 \pm 67.4(284.0-1754.0)$ & $466.8 \pm 16.4(284.0-1179.0)$ \\
\hline Mean annual FISH dose, mGy* (range) & $36.7 \pm 2.7(9.0-243.0)$ & $47.8 \pm 6.9(13.0-142.0)$ & $34.1 \pm 2.8(9.0-243.0)$ \\
\hline
\end{tabular}


Table 5 Discriminatory power of cumulative CBC results and TLD doses reported to screen 'High-Risk' radiation workers among 145 workers whose FISH doses were $\geq 250 \mathrm{mGy}$

\begin{tabular}{|c|c|c|c|c|c|}
\hline \multicolumn{6}{|c|}{ (A) Ratio of FISH doses vs TLD doses } \\
\hline \multirow{2}{*}{$\begin{array}{l}\text { FISH dose/TLD } \\
\text { dose* }\end{array}$} & \multicolumn{2}{|c|}{$\begin{array}{l}\text { HR radiation } \\
\text { workers }\end{array}$} & \multirow[b]{2}{*}{ Total } & \multirow[b]{2}{*}{$p$ Valuet } & \multirow[b]{2}{*}{ OR (95\% Cl) } \\
\hline & CBC-HR & TLD-HR & & & \\
\hline$\geq 5$ & 25 & 57 & 82 & \multirow[t]{3}{*}{$<0.001$} & \multirow{3}{*}{$\begin{array}{l}8.772 \\
(2.510 \text { to } 30.655)\end{array}$} \\
\hline$<5$ & 3 & 60 & 63 & & \\
\hline Total & 28 & 117 & 145 & & \\
\hline
\end{tabular}

(B) Annual FISH doses from working duration

\begin{tabular}{|c|c|c|c|c|c|}
\hline \multirow{2}{*}{$\begin{array}{l}\text { Annual FISH } \\
\text { dosef }\end{array}$} & \multicolumn{2}{|c|}{$\begin{array}{l}\text { HR radiation } \\
\text { workers }\end{array}$} & \multirow[b]{2}{*}{ Total } & \multirow[b]{2}{*}{ p Valuet } & \multirow[b]{2}{*}{ OR $(95 \% \mathrm{Cl})$} \\
\hline & CBC-HR & TLD-HR & & & \\
\hline$\geq 50 \mathrm{mGy}$ & 10 & 17 & 27 & \multirow[t]{3}{*}{0.010} & \multirow{3}{*}{$\begin{array}{l}3.268 \\
(1.291 \text { to } 8.270)\end{array}$} \\
\hline$<50 \mathrm{mGy}$ & 18 & 100 & 118 & & \\
\hline Total & 28 & 117 & 145 & & \\
\hline
\end{tabular}

*Ratio of FISH doses to TLD doses $\geq 5$ means 'high-risk' radiation workers because they had lower frequency of TLD-wearing during working periods.

tSignificant difference between the groups as determined by Pearson's $\chi^{2}$ test.

¥Annual FISH doses $\geq 50 \mathrm{mGy}$ means 'high-risk' radiation workers because they were exposed by IR during working periods.

CBC-HR, complete blood cell count-high risk; IR, ionising radiation; FISH, fluorescence in situ hybridisation; TLD-HR, thermoluminescent dosimeter-high risk.

that pooled results from 16 international laboratories found no significant effect of gender or race on translocation frequencies, but they did find a link with smoking habits, showing that smoking significantly modified the translocation frequency and age relationship. ${ }^{19}$ The frequency of stable translocations is thought to increase with age because these events are randomly induced throughout life and undergo little negative selection during mitosis. In this study, we showed that translocation frequencies in peripheral blood lymphocytes in the controls increased with age. Non-parametric Mann Whitney U-tests showed that cigarette smoking history and gender did not significantly affect translocation and dicentric frequency. Furthermore, multiple regression analyses did not support an association of smoking history or gender with genetic damage. However, multiple regression analyses did reveal that age and diagnostic CT scan/PET examination history were significantly associated with translocation frequencies in the controls (table 3). Interestingly, the significant effects of age on translocation frequency disappeared in the never-CT group, but the relationship between age and translocation frequencies remained in the ever-CT group. Furthermore, CT scan/PET history did not enhance CA frequencies in peripheral blood lymphocytes in high-risk radiation workers, but CT scan/PET history did enhance CA frequencies in healthy controls. This discrepancy is because the occupationally exposed individual dose was greater than the medical exposure in high-risk radiation workers. Age and working duration were also significantly associated with translocation frequencies.

Numerous studies indicate that IR at doses far below annual dose limits can increase the CA frequencies in the peripheral blood lymphocytes of occupationally exposed workers. ${ }^{24-27}$ In the present study, significant increase in dicentrics and translocations were observed in HR radiation workers compared with the controls (table 2). Furthermore, retrospective FISH doses and total cumulative TLD doses clearly increase with working duration in HR radiation workers (see online supplementary file). However, there is no relationship between retrospective FISH doses and total cumulative TLD doses in $145 \mathrm{HR}$ radiation workers who had a FISH dose $\geq 250 \mathrm{mGy}$. The slopes of the linear regression lines describing the relationship of FISH dose and TLD dose to working duration were $6.63(\mathrm{R}=0.235$, $\mathrm{p}=0.005)$ and $2.78(\mathrm{R}=0.372, \mathrm{p}<0.001)$, respectively. The slope of the linear regression lines for the relationship between FISH dose and cumulative TLD dose was $0.28 \quad(\mathrm{R}=0.073$, $\mathrm{p}=0.383)$. These results indicate that the frequency of TLD-wearing by workers during working periods was low. Additional evidence for this comes from the ratio of FISH doses to cumulative TLD doses. Thus, since the value of this ratio is $\geq 5$, TLD-wearing by workers during working periods was sporadic. Before engaging in radiation-related NDT testing, numerous workers receive only rudimentary radiation training. Indeed, from the results it appears that they have a poor knowledge of the biological health effects of radiation and radiation protection and a poor comprehension of the importance of dose monitoring. According to information obtained from an interview with HR radiation workers in the present study, a large number of workers did not wear their TLD badges all the time. This is despite regulations requiring radiographers to wear their individual dosimeters in the correct place at all times during radiography work and source manipulation. ${ }^{9}$ As a result the absorbed doses estimated by FISH analysis revealed that the whole body doses of HR radiation workers were markedly increased compared with TLD doses.

In this study, only one worker had exceeded $500 \mathrm{mGy}$ (mean value $=794 \mathrm{mGy}, 95 \%$ confidence level: 620-964 $\mathrm{mGy}$ ), the whole-body exposure threshold for acute haematopoietic syndrome or radiation sickness, ${ }^{28}$ according to the absorbed dose estimated by dicentric frequency. The dose in the same worker was estimated as $1754 \mathrm{mGy}$ (95\% confidence level: $1147-$ $2446 \mathrm{mGy}$ ) according to translocation frequency. However, his TLD accumulated dose was only $32.27 \mathrm{mSv}$ for about 18 years (data not shown). In total, 12 workers from the $297 \mathrm{HR}$ radiation workers $30 \%$ of the CBC-HR group and $3.3 \%$ of the TLD-HR group), with radiation work periods of $8-30$ years (mean 20.1 \pm 2.3 year), had exceeded $800 \mathrm{mGy}$ as estimated by translocation frequency. Fortunately, these workers had no sign or symptom of any disease including cancers in follow-up examinations following a Comprehensive Health Screening Programme.

Screening of high-risk workers who might have been exposed to IR is difficult unless the exposure is claimed. However, it is essential to maintain a successful health protection programme for radiation workers. Although three cases of leukaemia or myelodysplastic syndrome were found in NDT radiographers in South Korea, the health management system for industrial radiographers, which at present only records from personnel dosimeters and $\mathrm{CBC}$ results, is insufficient for purpose. In the case of the translocation assay, determination of the background level of translocation frequency from individual workers is very useful to reliably assess retrospective dosimetry for victims of prolonged and repetitive exposure. ${ }^{6}$ In addition, we have verified that a review of consecutive $\mathrm{CBC}$ results of individual workers by medical professionals is a reliable tool to screen high-risk radiation workers. The occupational radiation protection programme should be managed in collaboration with a relevant health discipline. By reviewing consecutive $\mathrm{CBC}$ results and performing periodical cytogenetic biodosimetry for radiation workers, the workers' protection programme may be improved.

Contributors JKL is a principal investigator of this study. She designed the study, directed its implementation and oversaw all aspects of the study, including patients and controls recruitment, funding, quality control of data and critical review of the 
manuscript. SSY and SHK were involved in cytogenetic dosimetry and prepared data sets for statistical analyses. SJ has performed the statistical analyses and interpreted the results and revised the manuscript critically for intellectual content. He wrote the manuscript and reviewed the whole document. MC jointly wrote the first draft of the paper, and provided critical comments on results analysis and interpretation including manuscript revision. WTK categorised HR radiation workers, and contributed to the interpretation of the results. All authors of this article have read and approved the final version submitted.

Funding This work was supported by the Nuclear Safety Research Programme through the Korea Foundation of Nuclear Safety, granted financial resources from the Nuclear Safety and Security Commission (number 1303027), Republic of Korea.

Competing interests None declared.

Patient consent Obtained.

Ethics approval The Institutional Review Board of the Korea Institute of Radiological and Medical Sciences.

Provenance and peer review Not commissioned; externally peer reviewed.

Open Access This is an Open Access article distributed in accordance with the Creative Commons Attribution Non Commercial (CC BY-NC 4.0) license, which permits others to distribute, remix, adapt, build upon this work non-commercially, and license their derivative works on different terms, provided the original work is properly cited and the use is non-commercial. See: http://creativecommons.org/ licenses/by-nc/4.0/

\section{REFERENCES}

1 International Atomic Energy Agency. Radiation Protection and Safety in Industrial Radiography. Safety Reports Series No. 13. Vienna: IAEA, 1999.

2 Korea Institute of Nuclear Safety. Nuclear laws of the Republic of Korea: nuclear safety act. Daejeon: KINS, 2013.

3 Ministry of Government Legislation. Korea's Labor laws: occupational safety and health act. Sejong-si: Republic of Korea, 2011.

4 Korea Institute of Nuclear Safety. Data cleaning of occupational radiation exposure and analysis of occupational radiation exposure (KINS/HR-1402). Daejeon: KINS, 2015.

5 Oh MS, Yoon JK, Kim HS, et al. Two case of Erythroleukemia and Myelodysplastic syndrome in a non-destructive inspector. Korean I Occup Environ Med 2011;23:471-9.

6 Cho MS, Lee JK, Bae KS, et al. Retrospective biodosimetry using translocation frequency in a stable cell of occupationally exposed to ionizing radiation. J Radiat Res 2015:56:709-16.

7 International Commission on Radiological Protection. The 2007 recommendations of the international commission on radiological protection. ICRP Publication 103: ICRP, 2007.

8 International Atomic Energy Agency. Cytogenetic dosimetry: applications in preparedness for and response to radiation emergencies. Vienna: IAEA-EPR, IAEA, 2011.

9 International Atomic Energy Agency. Radiation safety in industrial radiography. IAEA safety standards series No. SSG-11. Vienna: IAEA, 2011.
10 Tawn EJ, Whitehouse CA. Persistence of translocation frequencies in blood lymphocytes following radiotherapy: implications for retrospective radiation biodosimetry. J Radiol Prot 2003;23:423-30.

11 Lindholm C, Edwards A. Long-term persistence of translocations in stable lymphocytes from victims of a radiological accident. Int J Radiat Biol 2004;80:559-66.

12 Léonard A, Rueff J, Gerber GB, et al. Usefulness and limits of biological dosimetry based on cytogenetic methods. Radiat Prot Dosim 2005;115:448-54.

13 Pinto MM, Santos NF, Amaral A. Current status of biodosimetry based on standard cytogenetic methods. Radiat Environ Biophys 2010;49:567-81.

14 Beinke C, Meineke V. High potential for methodical improvements of FISH-based translocation analysis for retrospective radiation biodosimetry. Health Phys 2012;103:127-32.

15 Bonassi S, Forni A, Bigatti P, et al. Chromosome aberrations in hospital workers: evidence from surveillance studies in Italy (1963-1993). Am I Ind Med 1997;31:353-60.

16 Rozgaj R, Kasuba V, Sentija K, et al. Radiation-induced chromosomal aberrations and haematological alterations in hospital workers. Occup Med 1999;49:353-60.

17 Jha AN, Sharma T. Enhanced frequency of chromosome aberrations in workers occupationally exposed to diagnostic X-rays. Mutat Res 1991;260:343-8.

18 Whitehouse CA, Edwards AA, Tawn EJ, et al. Translocation yields in peripheral blood lymphocytes from control populations. Int I Radiat Biol 2005;81:139-45.

19 Sigurdson AJ, Ha M, Hauptmann M, et al. International study of factors affecting human chromosome translocations. Mutat Res 2008;652:112-21.

20 Ramsey MJ, Moore DH II, Briner JF, et al. The effects of age and lifestyle factors on the accumulation of cytogenetic damage as measured by chromosome painting. Mutat Res 1995;338:95-106

21 Tucker JD, Lee DA, Ramsey MJ, et al. On the frequency of chromosome exchanges in a control population measured by chromosome painting. Mutat Res 1994;313:193-202.

22 Tawn EJ, Whitehouse CA. Stable chromosome aberration frequencies in men occupationally exposed to radiation. J Radiol Protect 2003;23:269-78.

23 Pressl S, Romm H, Ganuly B, et al. Experience with FISH-detected translocations as an indicator in retrospective dose reconstructions. Radiat Prot Dosim 2000; 88:45-9.

24 Balakrishnan S, Rao SB. Cytogenetic analysis of peripheral blood lymphocytes of occupational workers exposed to low levels of ionizing radiation. Mutat Res 1999;442:37-42.

25 Mozdarani H, Hejazi A, Hejazi P. Chromosomal aberrations in lymphocytes of individuals with chronic exposure to gamma radiation. Arch Irn Med 2002:5:32-6.

26 Maffei F, Angelini S, Forti GC, et al. Spectrum of chromosomal aberrations in peripheral lymphocytes of hospital workers occupationally exposed to low doses of ionizing radiations. Mutat Res 2004;547:91-9.

27 Griciene B, Slapsyte G, Mierauskiene J. Cytogenetic monitoring of nuclear workers occupationally exposed to ionizing radiation. Radiat Prot Dosim 2014;15:10-19.

28 National Academy of Sciences. An evaluation of radiation exposure guidance for military operations: interim report. Washinton DC: National Academy Press, 1997. 